\title{
Evaluation of Patients' Experience Following Dental Implant Surgical Procedure
}

\author{
Ajayi Deborah Mojirade1, Gbadebo Shakeerah Olaide1, Ogunrinde Tunde Joshua1, \\ Sulaiman Amidu Omotayo ${ }^{1}$, Adebayo Gbenga Emmanuel ${ }^{2}$
}

\author{
${ }^{1}$ Department of Restorative Dentistry, College of Medicine, University of Ibadan/University College Hospital Ibadan, Oyo State, \\ Nigeria \\ ${ }^{2}$ Department of Restorative Dentistry, University College Hospital, Ibadan, Oyo state, Nigeria \\ Email:md_ajayi@yahoo.com, olaaris2k1@yahoo.com,tunde_ogunrinde2001@yahoo.com, tayooja@yahoo.co.uk, \\ dradebayogbenga@gmail.com
}

How to cite this paper: Mojirade, A.D., Olaide, G.S., Joshua, O.T., Omotayo, S.A. and Emmanuel, A.G. (2020) Evaluation of Patients' Experience Following Dental Implant Surgical Procedure. Open Journal of Stomatology, 10, 141-155.

https://doi.org/10.4236/ojst.2020.107015

Received: May 14, 2020

Accepted: July 6, 2020

Published: July 9, 2020

Copyright $\odot 2020$ by author(s) and Scientific Research Publishing Inc. This work is licensed under the Creative Commons Attribution International License (CC BY 4.0).

http://creativecommons.org/licenses/by/4.0/

(c) (i) Open Access

\begin{abstract}
Background: Patient's acceptability of dental implant prostheses may be influenced the fact that a surgical procedure is involved. Adequate relevant information by the dental professionals pre-surgery, is therefore, paramount to alleviating the fear of surgery and contribute positively to patient's ability to cope with post-surgical experience. This study, therefore, aimed at evaluating the postsurgical experience of the dental implant patients. As against what was expected, and relate this with the information given pre surgery. Methodology: Post treatment self-completed questionnaires were administered to consented patients that had dental implants placed between July 2017 and December 2019. The surgical procedure followed the standard protocol and data related to post-surgical experience were collected one week after the surgery to obtain information on the level of pain/discomfort and amount of swelling experienced following surgery. The effect of the information on coping ability following surgery was also assessed. Data were analyzed using descriptive statistics ( $p$ value $\leq 0.05$ ). Results: Twenty-seven patients received 44 implants to replace 48 teeth. The mean age of the patients was $45 \pm 16.3$ (SD) years. Teeth mostly replaced were the maxillary central incisors $(39.6 \%)$. The majority of the patients $77.7 \%$ reported to experience less pain/discomfort than expected and $66.6 \%$ had less swelling than expected. While $29.6 \%$ felt they had excellent explanation of what to expect, $51.9 \%$ said they had good explanation. The post-surgical experience between males and females was not statistically significant (pain: $\mathrm{p}=0.08$, swelling: $\mathrm{p}=0.64)$. However, the majority $(8 / 12)$ that had good to excellent information preoperatively, had significantly less discomfort than expected. Conclusion: Positive, encouraging and satisfactory experience of patients following implant surgical procedure is related to adequate and correct information pre-surgery.
\end{abstract}




\section{Keywords}

Evaluation, Patient's Experience, Implant Surgery, Pre-Surgical Information

\section{Introduction}

The use of osseointegrated implants as a foundation for prosthetic replacement of missing teeth has become widespread over the years [1], providing support to different forms of fixed and removable prostheses [2]. The introduction of dental implant-retained prostheses has resulted in a paradigm shift in the management of edentulism. It is of great value especially in the mandible, where advanced alveolar resorption and difficulty in providing stable, retentive, functionally comfortable prostheses is a big challenge [3]. Implant treatment has become highly predictable and successful probably due to the advancement in materials and the techniques of placement [1]. Furthermore, dental implant-supported prostheses have some advantages over other modalities in terms of function, comfort, biological compatibility, sustainability as well as relative cost-effectiveness [4]. However, high initial cost of dental implants and the fact that surgical procedure is required, may influence patients' acceptance of implant as a replacement option [5].

Patient's satisfaction with the outcome of implant surgery and prosthetic fabrication can be influenced by their expectations and pain experienced during and after the surgery. In addition, the degree of preoperative information provided for "informed consent," satisfaction with comfort, and appearance are factors influencing overall treatment outcome satisfaction [6].

Other factors that may affect acceptance of implants are dental anxiety as well as fear of pain [7]. It has been found that patients with high phobia for surgery do not choose dental implant due to surgical procedure involved [8]. Therefore, in motivating patients towards accepting dental implant, specialists need to be aware of patients' anxiety towards the choice and their experience following the dental implant placement.

Consequent to prolonged time involved and high cost of implant treatment, patients most times have high expectations for satisfactory treatment outcome [9] [10]. In order to avoid over-expectations and undue dissatisfaction with the treatment outcome, it is fundamental that adequate and thorough explanation of the procedures involved be made to the patients. Relevant information regarding what to expect during and after the surgical procedure is paramount to patient's eventual satisfaction. Though initial information about dental implant surgery is often obtained from relatives, friends, printed media or internet [11] [12], findings from various researches have shown that patients seek more detailed information from dentists and nurses about implant treatment before undergoing surgery [11] [13]. The detailed information provided by dental professionals are either passed across by conventional face-to-face verbal information or through the use of audiovisuals, though the latter has been found to generate greater an- 
xiety and fear in patients undergoing implant surgery [14] [15].

Furthermore, studies [16] [17] have shown that patient's satisfaction is significantly determined by the quality of interpersonal communication between patient and healthcare providers. Thus, it may be significant to correlate the amount of such information given to patient prior to implant surgery with their postsurgical experience and see how such information assisted them in coping with their expectations following the surgery. Therefore, the aim of this study was to record patients experience following dental implant surgery as well as how the pre-surgery information given helped with their expectations.

\section{Methodology}

This prospective study involved patients that had dental implants placed at the dental implantology center of the University College Hospital Ibadan, between July 2017 and December 2019. Healthy adult patients $\geq 18$ years (those that were not incapacitated by any chronic medical condition) that gave informed consent to participate in the study were consecutively recruited. The study protocol was approved by the UI/UCH Ethics review board. All the patients were given detailed basic explanation as regards the surgical and restorative phases by the Implant team which comprises of oral surgeons, restorative dentists and a periodontologist. Each patient was given the opportunity to ask as many questions as possible before the informed consent was obtained after confirming their satisfaction with the information.

A data collection form was designed by the authors who are specialists involved in implantology treatment at the study centre. Following both face and content validity of the form, it was pre-tested among 5 patients who were not part of this study, to detect and remove any ambiguity. The form comprised of 2 parts; part A was used to record the age, gender, habit (smoking, bruxism), socioeconomic status (SES) and medical condition of the patients. The SES was defined into high, middle and low, using the modified version of occupational stratification criteria of Famuyiwa and Olorunsola (1998) [18]. In addition, number and position of implant placed, the protocol for implant placement whether immediate or conventional were recorded. Part B asked questions on patients' rating of their experience of discomfort whether significantly/slightly less than expected same or significantly/slightly more. Furthermore, it sought for patient evaluation of pre-operative information (not sufficient, sufficient, good or excellent) in relation to their experience after surgery.

Implant placement was performed according to standard surgical protocols under local anaesthesia. All patients were prescribed: an antibiotic (Clindamycin $300 \mathrm{mg}$ ) twice daily for 5 days, Diclofenac potassium $50 \mathrm{mg}$ twice daily for 3 days, Vitamin C $1000 \mathrm{mg}$ daily for 2 weeks. Both verbal and written post-surgical instructions were given with emphasis on maintenance of good oral hygiene. At the one-week review visit, the patients independently completed the part B of the data collection form. 
Data analysis was carried out using statistical package for social sciences (IBM SPSS for window: version 23). Pearson's Chi square test was used to test association between categorical variables while independent t-test (with reverse test for Equality of variances assumed) was employed to compare the means of pain/swelling experienced between genders. The significance level was put at $\mathrm{p} \leq 0.05$.

\section{Results}

Dental implant treatment was done for 27 patients between July 2017 and December 2019. The patients included 13 (48.1\%) males and 14 (51.9\%) females aged between 18 and 71 years, with mean age of $45.0 \pm 16.3$ (SD) years. Most of the patients (51.9\%) fell within the age group 41 - 60 years. The majority $(66.7 \%)$ were married while most (48.2\%) were in the middle socioeconomic class (Table 1 ). The majority (59.3\%) had no systemic illness while hypertension was the commonest systemic disease as seen in $25.9 \%$ of the patients (Table 1 ). None of the patients was a smoker or had any oral parafunctional habits.

Table 1. The Characteristics of dental implant patients.

\begin{tabular}{|c|c|c|}
\hline Gender & $\mathbf{N}$ & $\%$ \\
\hline Male & 1 & 48.1 \\
\hline Female & 14 & 51.9 \\
\hline \multicolumn{3}{|l|}{ Age Group } \\
\hline$<20$ & 3 & 11.1 \\
\hline $21-40$ & 6 & 22.2 \\
\hline $41-60$ & 14 & 51.9 \\
\hline $61-80$ & 4 & 14.8 \\
\hline \multicolumn{3}{|c|}{ Mean Age $\pm S D=45 \pm 16.3$ years } \\
\hline \multicolumn{3}{|l|}{ Marital Status } \\
\hline Single & 8 & 29.6 \\
\hline Married & 18 & 66.7 \\
\hline Widow & 1 & 3.7 \\
\hline \multicolumn{3}{|l|}{ SES } \\
\hline High & 10 & 37.0 \\
\hline Middle & 13 & 48.2 \\
\hline Low & 4 & 14.8 \\
\hline \multicolumn{3}{|l|}{ Systemic Condition } \\
\hline Nil of Note & 16 & 59.3 \\
\hline Hypertensive & 7 & 25.9 \\
\hline Peptic Ulcer & 2 & 7.4 \\
\hline Epilepsy & 1 & 3.7 \\
\hline Diabetic Mellitus & 1 & 3.7 \\
\hline
\end{tabular}


The total number of teeth replaced with implants in these patients was 48 , though only 44 implants were placed indicating a mean of $1.6 \mathrm{implant/patient}$ (some patients had implant-retained bridges). The maxillary central incisors were the most commonly replaced with upper right and left centrals accounting for $20.8 \%$ and $18.8 \%$ respectively. Posteriorly, the maxillary right second premolar and the mandibular right first molar were the predominantly replaced teeth $(8.3 \%$ in each case) Table 2.

Figure 1 shows that the majority of the implants were placed conventionally while about one-third was done using immediate implant placement technique.

Table 2. Frequency distribution of teeth replaced with implant in subjects.

\begin{tabular}{ccc}
\hline Teeth replaced & Frequency & Percentages \% \\
\hline Upper right 1 & 10 & 20.8 \\
Upper right 2 & 3 & 6.20 \\
Upper right 3 & 1 & 2.10 \\
Upper right 4 & 2 & 4.20 \\
Upper right 5 & 4 & 8.30 \\
Upper left 1 & 9 & 18.8 \\
Upper left 2 & 4 & 8.30 \\
Upper left 6 & 1 & 2.10 \\
Lower right 1 & 1 & 2.10 \\
Lower right 6 & 4 & 8.30 \\
Lower right 7 & 1 & 2.10 \\
Lower left 1 & 1 & 2.10 \\
Lower left 3 & 1 & 2.10 \\
Lower left 5 & 1 & 2.10 \\
Lower left 6 & 2 & 4.20 \\
Lower left 7 & 3 & 6.20 \\
Total & 48 & 100 \\
\hline
\end{tabular}

\section{Mode of Placement}

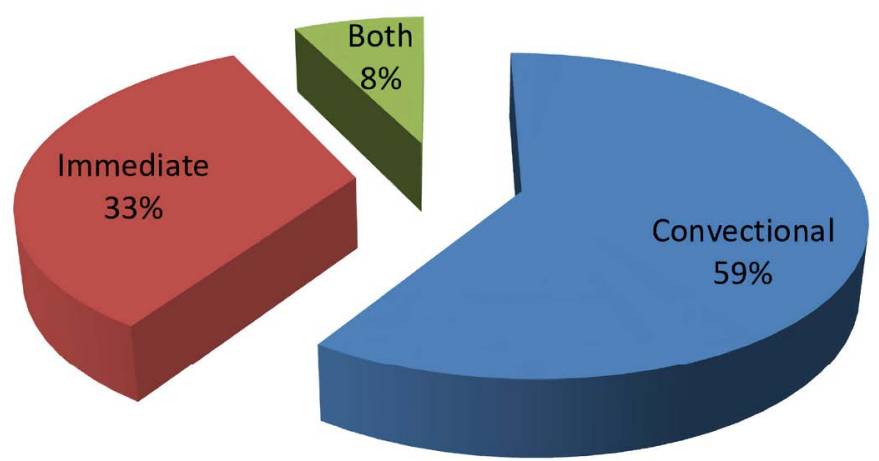

Figure 1. Mode of placement. 
Table 3 shows the frequency distribution of the post-surgical experience of the patients. The majority (77.7\%) of the patients reported that the pain/discomfort experienced was less (either significantly or slightly) than expected while only one patient $(3.7 \%)$ claimed to have experienced more pain/discomfort than expected. Similarly, most (66.6\%) patients had less swelling than expected.

About one third (29.6\%) felt they had excellent explanation of what to expect while a high majority (51.9\%) had good explanation. However, $7.4 \%$ of the patients felt the information given were not sufficient to meet their needs (Figure 2).

With regards to gender variation in post-surgical experience, male patients had greater mean values for both pain and swelling (2.31 and 2.23 respectively) even though the difference was not statistically significant $(\mathrm{p}=0.08$ and 0.64 respectively, Table 4).

Table 5 shows that among the patients that had significantly less discomfort than expected, the majority $(8 / 12)$ had good to excellent information preoperatively. The majority of the patient 14 (51.9\%) had good explanation before the procedure and $11(40.7 \%)$ of them had less discomfort. However, two patients that claimed to have received excellent explanation reported to have experienced slightly more pain than expected. Though, there was no statistically significant difference in the correlation between the information and the pain/discomfort experienced.

Table 3. Distribution of patient's experience following implant surgery.

\begin{tabular}{llll}
\hline \multicolumn{1}{c}{$\begin{array}{c}\text { Rating of discomfort } \\
\text { following surgery }\end{array}$} & $\%$ & $\begin{array}{l}\text { Amount of swelling } \\
\text { experienced following surgery }\end{array}$ & $\%$ \\
\hline $\begin{array}{l}\text { Significantly less discomfort than } \\
\text { that expected }\end{array}$ & 44.4 & $\begin{array}{l}\text { Significantly less swelling than I } \\
\text { had expected }\end{array}$ & 40.7 \\
$\begin{array}{l}\text { Slightly less discomfort than I had } \\
\text { expected }\end{array}$ & 33.3 & $\begin{array}{l}\text { Slightly less swelling than I had } \\
\text { expected }\end{array}$ & 25.9 \\
$\begin{array}{l}\text { About the same amount of } \\
\text { discomfort that I had expected }\end{array}$ & 11.1 & $\begin{array}{l}\text { About the same swelling that I had } \\
\text { expected }\end{array}$ & 18.5 \\
$\begin{array}{l}\text { Slightly more discomfort than I had } \\
\text { expected }\end{array}$ & 7.40 & $\begin{array}{l}\text { Slightly more swelling than I had } \\
\text { expected }\end{array}$ & 11.1 \\
$\begin{array}{l}\text { Significantly more discomfort than I } \\
\text { had expected }\end{array}$ & 3.70 & $\begin{array}{l}\text { Significantly more swelling than I } \\
\text { had expected }\end{array}$ & 3.70 \\
\hline
\end{tabular}

Table 4. Gender variation in post implant surgery experience.

\begin{tabular}{cccc}
\hline Pain/Discomfort Experienced & Mean & t-test value & p-value \\
Male & $2.31 \pm 1.18$ & 1.80 & 0.08 \\
Female & $1.57 \pm 0.94$ & & \\
Swelling & & & \\
Male & $2.23 \pm 1.30$ & 0.50 & 0.62 \\
Female & $2.00 \pm 1.11$ & & \\
\hline
\end{tabular}


Table 5. Correlation between pre-operative information received by the patient and the post-operative pain experienced.

\begin{tabular}{|c|c|c|c|c|c|c|c|c|c|c|c|c|c|}
\hline & & \multicolumn{8}{|c|}{$\begin{array}{l}\text { How did the information you were given before the procedure } \\
\text { helped you to cope with your experience? }\end{array}$} & \multirow{2}{*}{\multicolumn{2}{|c|}{ Total }} & \multirow{3}{*}{$\begin{array}{c}\mathrm{R} \\
\text { Spearman } \\
\text { Correlation }\end{array}$} & \multirow{3}{*}{$\begin{array}{c}\mathrm{p} \\
\text { value }\end{array}$} \\
\hline & & \multicolumn{2}{|c|}{$\begin{array}{c}\text { It was not } \\
\text { sufficient to } \\
\text { meet my needs }\end{array}$} & \multicolumn{2}{|c|}{$\begin{array}{l}\text { Sufficient but } \\
\text { would have } \\
\text { preferred more } \\
\text { information }\end{array}$} & \multicolumn{2}{|c|}{$\begin{array}{l}\text { Good explanation } \\
\text { of what to expect } \\
\text { with the treatment }\end{array}$} & \multicolumn{2}{|c|}{$\begin{array}{l}\text { Excellent } \\
\text { explanation of } \\
\text { what to expect } \\
\text { vith the treatment }\end{array}$} & & & & \\
\hline & & $\mathrm{N}$ & $\%$ & $\mathrm{~N}$ & $\%$ & $\mathrm{~N}$ & $\%$ & $\mathrm{~N}$ & $\%$ & $\mathrm{~N}$ & $\%$ & & \\
\hline \multirow{6}{*}{$\begin{array}{c}\text { How would } \\
\text { you rate your } \\
\text { pain/discomfor } \\
\text { following } \\
\text { surgery? }\end{array}$} & $\begin{array}{l}\text { Significantly less } \\
\text { discomfort than I had } \\
\text { expected }\end{array}$ & 2 & 7.4 & 2 & 7.4 & 4 & 14.8 & 4 & 14.8 & 12 & 44.4 & 0.230 & 0.248 \\
\hline & $\begin{array}{l}\text { Slightly less } \\
\text { discomfort than I had } \\
\text { expected }\end{array}$ & 0 & 0 & 1 & 3.7 & 7 & 25.9 & 1 & 3.7 & 9 & 33.3 & & \\
\hline & $\begin{array}{l}\text { tAbout the same } \\
\text { amount of discomfort } \\
\text { that I had expected }\end{array}$ & 0 & 0 & 0 & 0 & 2 & 7.4 & 1 & 3.7 & 3 & 11.1 & & \\
\hline & $\begin{array}{l}\text { Slightly more than I } \\
\text { had expected }\end{array}$ & 0 & 0 & 0 & 0 & 0 & 0 & 2 & 7.4 & 2 & 7.4 & & \\
\hline & $\begin{array}{l}\text { Significantly more } \\
\text { than I had expected }\end{array}$ & 0 & 0 & 0 & 0 & 1 & 3.7 & 0 & 0 & 1 & 3.7 & & \\
\hline & Total & 2 & 7.4 & 3 & 11.1 & 14 & 51.9 & 8 & 29.6 & 27 & 100.0 & & \\
\hline
\end{tabular}

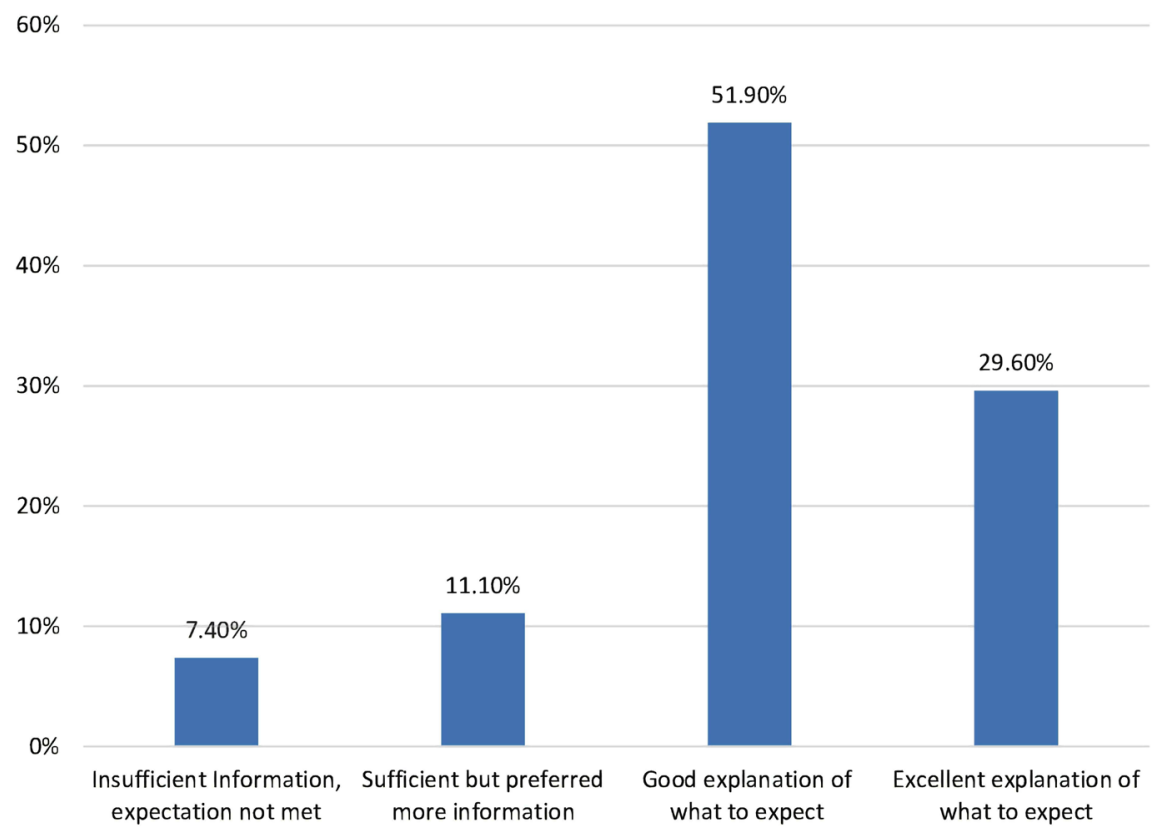

Figure 2. How information before procedure met patient's expectations.

\section{Discussion}

The use and acceptance of dental implant as a replacement for missing tooth, has been on the increase especially in the developed world [19] [20]. In Nigeria, though the number of patients going for this option of tooth replacement may be 
low, it is pertinent to know the experience of the few patients in relation to the treatment, as studies [11] [21] have shown that many people get information as regarding different options from friends, relatives or other patients. Apart from getting feedback from the patients, knowing their experience will help towards the drive for more acceptance of implant surgery in our environment. The objective of this study was thus to know the view of the patients who had implant surgery in our facility with respect to the surgery experience as against what was expected, as well as effect of information given pre surgery.

The majority of the patients seen were females and the most commonly replaced teeth were the maxillary central incisors. This follows what has been reported in previous study by Ajayi et al. [22], from same center and also in accordance with some other studies [23] [24] that showed anterior teeth as being the most frequently replaced teeth with dental implants. This may not be unconnected to fulfilling aesthetics as a major reason for tooth replacement especially in females [25].

Also, majority of the patient had no systemic disease. This is not surprising, however, because case selection in implant surgery is very critical to obtaining a good outcome [26] [27] [28]. Some studies [29] [30] have pointed out that effect of systemic diseases on the outcome of implant surgery may be limited. However, Ajayi et al. [22] reported uncontrolled diabetes and HBSS as possible risk factors associated with healing and failure of dental implant recorded in their study. Nevertheless, good case selection in terms of quality and quantity of bone is paramount for better dental implant survival [31] [32].

The post implant surgery experience in this study was positive with most of the patients $(77.7 \%)$ having significantly less or slightly less than expected pain. Pain and discomfort are amongst the major factors/symptoms used by patients to assess success of most dental surgeries including dental implant surgery. These are also among factors that can influence patients experience and overall satisfaction with dental implants [33] [34] [35] thus the less these symptoms the more positive the experience and the better the satisfaction post implant surgery [33].

In accordance to the findings in this study, Nogueira et al. [36] in a qualitative study reported that most patients had positive experience and less pain than expected. Similarly, Al Kabbaz et al. [37] reported that patients had mild pain than expected and this pain also reduced gradually with time. The result in this study may partially be due to the fact that majority (59\%) of the cases were single implant placed conventionally. This is also corroborated by Al Kabbaz et al. [37] who reported that higher pain/discomfort is associated with multiple implant insertion. Patients that received multiple implants were found to be 1.3 times more likely to experience pain during surgery compared to those for single implant.

In addition, post-operative swelling is another factor that may influence postsurgery experience as most patients fear this, especially in the facial region where aesthetics is paramount. Similar to this study, Sanjay et al. [38] reported mild swelling post implant surgery. Only one of the participants (3.7\%) in the present study 
experienced significant swelling than expected. This may be attributed to effective compliance to the post-operative instruction of placing ice pack on surgical site by the patient, which is ensured regularly at the study center. This has been found to significantly reduce post-operative swelling when well adhered to [39].

Furthermore, a gender difference in patients' experience was recorded in this study in relation to both pain and swelling with males having greater mean values than females (2.31 and 2.23 respectively) indicating that men reported to experience more pain than female. This finding is in contrast to the study by McCrea [33] who found a significant gender difference, with male having higher comfort post implant surgery. Though most studies [40] [41] reported men to have higher pain threshold, women could also experience less discomfort or pain [42]. There may, therefore, be no clear cut agreement on gender disparity in post-surgical treatment.

Additionally, in assessing how the information provided pretreatment met the need of the patients, our study showed that the majority of the patients (81.5\%) had good to excellent information. Also, those that had significantly less discomfort (66\%) and generally those with less discomfort and pain reported they had good to excellent preoperative information, though not significant. Correspondingly, McCrea et al. [33] have also reported significant relationship between information received pre surgery and patients' comfort. In this era of information on various dental procedures including dental implant through various forms of media [11] [43], it is pertinent on the dentists to give adequate information to the patients that show interest prior treatment.

Explanation of the procedure, possible complications and expectation postsurgery, both immediate and long term may help in alleviating the fear for surgery and prepare the patients psychologically. Also, a well-informed patient may not have unrealistic expectations post treatment as this may also influence the experience. Most importantly, adequate information which should include the level of discomfort and pain a patient must expect with dental implant treatment [31], is necessary from the professionals. This will also help throw light on any possible misleading information received through media which may give unrealistic expectations [11] [43].

This study has thus added to knowledge, that adequate information from the professionals prior to surgery gives positive experience post-surgery as the majority of the patients claimed the information given met their needs. However, some felt they needed more information, therefore, there is room for improvement in the amount and quality of information given to the patients. Though not considered in this study, positive experience with implant surgery may lead to patients' future implant treatment consideration [34] and possible recommendation to other people.

Limitation of this study includes the low sample size which is due to number of patients that showed interest and were treated during the study period. Another limitation is the single center report. Therefore, further studies that will include a larger sample size will be better to generalize the result. 


\section{Conclusion}

Within the limitation of the study, it can be concluded that a positive, encouraging and satisfactory experience of patients following implant surgical procedure is related to adequate and correct pre-treatment information. This may also contribute further to better acceptance of dental implant in our environment as a significant option for tooth replacement, considering the fact that experiences often shared among people may influence their decisions on many things.

\section{Conflicts of Interest}

The authors declare no conflicts of interest regarding the publication of this paper.

\section{References}

[1] Levin, L., Ofec, R., Grossmann, Y. and Anner, R. (2011) Periodontal Disease as a Risk for Dental Implant Failure over Time: A Long-Term Historical Cohort Study. Journal of Clinical Periodontology, 38, 732-737. https://doi.org/10.1111/j.1600-051X.2011.01745.x

[2] Van eekeren, P., Aartman, I., Tahmaseb, A. and Wismeijer, D. (2016) The Effect of Implant Placement in Patients with Either Kennedy Class II and III on Oral Health-Related Quality of Life: A Prospective Clinical Trial. Journal of Oral Rehabilitation, 43, 291-296. https://doi.org/10.1111/joor.12370

[3] Vercruyssen, M., Marcelis, K., Coucke, W., Naert, I. and Quirynen, M. (2010) Long-Term, Retrospective Evaluation (Implant and Patient-Centred Outcome) of the Two Implants-Supported Overdenture in the Mandible. Part 1: Survival Rate. Clinical Oral Implants Research, 21, 357-365. https://doi.org/10.1111/j.1600-0501.2009.01849.x

[4] Kamankatgan, S., Pimkhaokham, A. and Krisdapong, S. (2017) Patient-Based Outcomes Following Surgical Implant Placements. Clinical Oral Implants Research, 28, 17-23. https://doi.org/10.1111/clr.12608

[5] Kim, Y.-K., Kim, H.-S., Yi, Y.-J. and Yun, P.-Y. (2014) Evaluation of Subjective Satisfaction of Dental Implant Patients. Journal of the Korean Association of Oral and Maxillofacial Surgeons, 40, 130-134. https://doi.org/10.5125/jkaoms.2014.40.3.130

[6] Dong, H., Zhou, N., Liu, H., Huang, H., Yang, G., Chen, L., et al. (2019) Satisfaction Analysis of Patients with Single Implant Treatments Based on a Questionnaire Survey. Patient Preference and Adherence, 13, 695-704. https://doi.org/10.2147/PPA.S201088

[7] Ellis, J.S., Levine, A., Bedos, C., Mojon, P., Rosberger, Z., Feine, J., et al. (2011) Refusal of Implant Supported Mandibular Overdentures by Elderly Patients. Gerodontology, 28, 62-68. https://doi.org/10.1111/j.1741-2358.2009.00348.x

[8] Lalabonova, C.K. (2015) Impact of Dental Anxiety on the Decision to Have Implant Treatment. Folia Medica (Plovdiv), 57, 116-121. https://doi.org/10.1515/folmed-2015-0029

[9] Mohammad, K., Shaifulizan, A., Rehana, B., Tiffany Tang, S., Justin, W. and Soumendra, S. (2015) Dental Implant-Perceiving Patients' Satisfaction in Relation to Clinical and Electromyography Study on Implant Patients. PLOS ONE, 10, e140438. https://doi.org/10.1371/journal.pone.0140438 
[10] Strassburger, C., Heydecke, G. and Kerschbaumi, T. (2004) Influence of Prosthetic and Implant Therapy on Satisfaction and Quality of Life: A Systematic Literature Review. International Journal of Prosthodontics, 17, 83-93.

[11] Pommer, B., Zechner, W., Watzak, G., Ulm, C., Watzek, G. and Tepper, G. (2011) Progress and Trends in Patients' Mindset on Dental Implants. I: Level of Information, Sources of Information and Need for Patient Information. Clinical Oral Implants Research, 22, 223-229. https://doi.org/10.1111/j.1600-0501.2010.02035.x

[12] Kashbour, W.A., Rousseau, N.S., Thomason, J.M. and Ellis, J.M. (2018) Provision of Information on Dental Implant Treatment: Patient's Thoughts and Experiences. Clinical Oral Implants Research, 29, 309-319. https://doi.org/10.1111/clr.13118

[13] Kashbour, W.A., Rousseau, N.S., Ellis, J.S. and Thomason, J.M. (2015) Patient's Experiences of Dental Implant Treatment: A Literature Review of Key Qualitative. Journal of Dentistry, 43, 789-797. https://doi.org/10.1016/j.jdent.2015.04.008

[14] Camacho-Alonso, F., Vilaplana-Vivo, J., Caballero-Guerrero, P.M., Pato-Mourelo, J. and Sanchez-Siles, M. (2019) Impact of Audiovisual Information on Anxiety and Fear in Patients Undergoing Dental Implant Treatment. Clinical Implant Dentistry and Related Research, 21, 1189-1198. https://doi.org/10.1111/cid.12851

[15] Kazancioglu, H.O., Dahhan, A.A. and Acar, A.H. (2017) How Could Multimedia Information about Dental Implant Surgery Effects Patient's Anxiety Levels? Medicina Oral Patologia Oral y Cirugia Bucal, 22, e102-e107. https://doi.org/10.4317/medoral.21254

[16] Ben-Sira, Z. (1980) Affective and Instrumental Components in the Physician-Patient Relationship: An Additional Dimension of Interaction Theory. Journal of Health and Social Behaviour, 21, 170-180. https://doi.org/10.2307/2136736

[17] Ross, C.E. and Duff, R.S. (1982) Returning to the Doctor: The Effect of Client Characteristic, Type of Practice, and Experiences with Care. Journal of Health and Social Behavior, 23, 119-131. https://doi.org/10.2307/2136509

[18] Famuyiwa, O.O. and Olorunshola, D.A. (1998) Some Family Factors in Sickle Cell Anemia in Lagos, Nigeria. Nigerian Medical Practitioner, 35, 70-73.

[19] Narby, B., Kronström, M., Söderfeldt, B. and Palmqvist, S. (2008) Changes in Attitudes toward Desire for Implant Treatment: A Longitudinal Study of a Middle-Aged and Older Swedish Population. International Journal of Prosthodontics, 21, 481-485.

[20] Andreescu, C.F. (2017) Attitude of Accepting Dental Implant Treatment among Aged Patients. Mouth and Teeth, 1, 1-2. https://doi.org/10.15761/MTJ.1000104

[21] Gbadebo, S.O., Lawal, F.B., Sulaiman, A.O. and Ajayi, D.M. (2014) Dental Implant as an Option for Tooth Replacement. The Awareness of Patients at a Tertiary Hospital in a Developing Country. Contemporary Clinical Dentistry, 5, 302-306. https://doi.org/10.4103/0976-237X.137914

[22] Ajayi, D.M., Abiodun-Solanke, I., Gbadebo, S.O., Fasola, A.O., Dosumu, O.O. and Arotiba, J.T. (2014) Dental Implant Treatment at a Nigerian Teaching Hospital. Journal of the West African College of Surgeons, 4, 89-99.

[23] Nixon, K.C., Chen, S.T. and Ivanovski, S. (2009) A Retrospective Analysis of 1000 Consecutively Placed Implants in Private Practice. Australian Dental Journal, 54, 123-129. https://doi.org/10.1111/j.1834-7819.2009.01104.x

[24] Parzham, V., Judge, R. and Bailey, D. (2018) A Five-Year Retrospective Assay of Implant Treatments and Complications in Private Practice: Restorative Treatment Profiles of Long-Span, Implant-Supported Fixed and Removable Dental Prostheses. The International Journal of Prosthodontics, 31, 211-222.

https://doi.org/10.11607/ijp.5553 
[25] Armalaite, J., Jarutiene, M., Vasiliauska, A., Sidlauska, A., Svalkauskiene, V., Sidlauska, M., et al. (2108) Smile Aesthetics as Perceived by Dental Students: A Cross-Sectional Study. BMC Oral Health, 18, 225. https://doi.org/10.1186/s12903-018-0673-5

[26] Thomas, B. and Thomas, F.F. (2003) Implants in the Medically Compromised Patient. Critical Reviews in Oral Biology \& Medicine, 14, 305-316. https://doi.org/10.1177/154411130301400407

[27] Sharma, D., Deshpande, N., Dave, D., Shah, M. and Shah, S. (2013) Case Selection in Dental Implant Therapy. RRJDS, 1, 26-29. https://doi.org/10.4103/2347-6486.238977

[28] Alani, A., Bishop, K., Djemal, S. and Renton, T. (2012) Guidelines for Selecting Appropriate Patients to Receive Treatment with Dental Implants: Priorities for the NHS.

[29] Michael, M.B., Norbert, C. and Andrea, M.P. (2009) Systemic Conditions and Treatments as Risks for Implant Therapy. The International Journal of Oral \& Maxillofacial Implants, 23, 12-27.

[30] Donos, N. and Calciolari, E. (2014) Dental Implants in Patients Affected by Systemic Diseases. British Dental Journal, 217, 425-430. https://doi.org/10.1038/sj.bdj.2014.911

[31] Wakimoto, M., Matsumura, T., Ueno, T., Mizukawa, N., Yanagi, Y. and Iida, S. (2011) Bone Quality and Quantity of the Anterior Maxillary Trabecular Bone in Dental Implant Sites. Clinical Oral Implants Research, 23, 1314-1319. https://doi.org/10.1111/j.1600-0501.2011.02347.x

[32] Mittal, Y., Jindal, G. and Garg, S. (2016) Bone Manipulation Procedures in Dental Implants. Indian Journal of Dentistry, 7, 86-94. https://doi.org/10.4103/0975-962X.184650

[33] McCrea, J. and Shane, J. (2017) An Analysis of Patient Perceptions and Expectations to Dental Implants: Is There a Significant Effect on Long-Term Satisfaction Levels? International Journal of Dentistry, 2017, Article ID: 8230618. https://doi.org/10.1155/2017/8230618

[34] Gomez-de, D.R., Cutando-Soriano, A., Montero-Martin, J., Prados-Frutos, J.C. and Lopez-Valverde, A. (2014) State Anxiety and Depression as Factors Modulating and Influencing Postoperative Pain in Dental Implant Surgery. A Prospective Clinical Survey. Medicina Oral Patologia Oral y Cirugia Bucal, 19, e592-e597. https://doi.org/10.4317/medoral.19685

[35] Kuroi, R., Minakuchi, H., Hara, E.S., Akawakami, A., Maekawa, K., Okada, H., et al. (2015) A Risk Factor Analysis of Accumulated Postoperative Pain and Swelling Sensation after Dental Implant Surgery Using a Cellular Phone-Based Real-Time Assessment. Journal of Prosthodontic Research, 59, 194-198.

https://doi.org/10.1016/j.jpor.2015.05.003

[36] Nogueira, T.E., Dias, D.R., Rios, L.F., Luiza, A., Silva, A.L.M., Jordao, L.M.R., et al. (2019) Perceptions and Experiences of Patients Following Treatment with Single Implant Mandibular Overdentures: A Qualitative Study. Clinical Oral Implants Research, 30, 79-89. https://doi.org/10.1111/clr.13394

[37] Al-Khabbaz, K., Terrence, J.G. and Khalaf, F.A. (2007) Assessment of Pain Associated with the Surgical Placement of Dental Implants. Journal of Periodontology, 78, 239-246. https://doi.org/10.1902/jop.2007.060032

[38] Sanjay, B., Kumar, S. and Singh, H.P. (2107) Systemic Assessment of Patients Undergoing Dental Implant Surgeries: A Trans- and Post-Operative Analysis. Nigerian Journal of Surgery, 23, 58-62. https://doi.org/10.4103/1117-6806.199966 
[39] Urban, T. and Wenzel, A. (2010) Discomfort Experienced after Immediate Implant Placement Associated with Three Different Regenerative Techniques. Clinical Oral Implants Research, 21, 1271-1277. https://doi.org/10.1111/j.1600-0501.2010.01943.x

[40] Mogil, J.S. (2012) Sex Differences in Pain and Pain Inhibition: Multiple Explanations of a Controversial Phenomenon. Nature Reviews Neuroscience, 13, 859-866. https://doi.org/10.1038/nrn3360

[41] Bartley, E.J. and Fillingim, R.B. (2013) Sex Differences in Pain: A Brief Review of Clinical and Experimental Findings. British Journal of Anaesthesia, 111, 52-58. https://doi.org/10.1093/bja/aet127

[42] Morin, C., Lund, J.P., Villarroel, T., Clokie, C.M. and Feine, J.S. (2000) Differences between the Sexes in Post-Surgical Pain. Pain, 85, 79-85.

https://doi.org/10.1016/S0304-3959(99)00248-1

[43] Rustemeyer, J. and Bremerich, A. (2007) Patients' Knowledge and Expectations Regarding Dental Implants: Assessment by Questionnaire. International Journal of Oral and Maxillofacial Surgery, 36, 814-817.

https://doi.org/10.1016/j.ijom.2007.05.003 


\section{Appendix}

\section{Questionnaire:}

Evaluation of Patients' Experience Following Dental Implant Surgical

\section{Procedure}

Dear participant,

This questionnaire is set out to know the experience of our patients following implant treatment, and also to know how well informed you were before the procedure. The study outcome will assist us to give better and improved treatment to patients.

Your participation is voluntary and would be treated with absolute confidentiality.

\section{Part A: Bio data}

\section{Date \\ Case note No \\ Phone No}

1) Gender: Male $\square$ Female

2) Age (years):

3) Occupation:

4) Educational level: i) No formal education $\square$ ii) Primary $\square$ iii) Secondary iv) Post Secondary $\square$ v) Tertiary $\square$ vi) others (please specify) .

5) Marital status: i) Single $\square$ ii) Married $\square$ iii) Divorced $\square$ (iv) Widowed v) Separate

6) Medical History:

7) Type of Implant-supported prosthesis: (To be filled by Clinician)

8) Tooth/teeth replaced:

9) Date of implant insertion

10) How many teeth are missing?
a) One
b) Two or three
c) 4 or more missing teeth but one or more in each jaw
d) All teeth missing in at least one jaw
11) Mode of placement of implant (to be filled by the Clinician)

\section{Part B}

12) How would you rate your pain/discomfort following surgery?
a) Significantly less pain/discomfort than I had expected
b) Slightly less pain/discomfort than I had expected
c) About the same amount of pain/discomfort that I had expected
d) Slightly more than I had expected
e) Significantly more than I had expected
13) How much swelling did you experience following surgery?
a) Significantly less swelling than I had expected
b) Slightly less swelling than I had expected
c) About the same swelling that I had expected
d) Slightly more swelling than I had expected
e) Significantly more swelling than I had expected 
14) How did the information you were given before the procedure meet your expectation and help you to cope after the surgery.

a) It was not sufficient to meet my needs and expectation

b) Sufficient, but would have preferred more information

c) Good explanation of what to expect after surgery

d) Excellent explanation of what to expect after surgery

Thank you. 